\title{
ACOMPANHAMENTO ODONTOLÓGICO NA ONCOLOGIA: UMA PARCERIA ENTRE ENSINO E SERVIÇO
}

Larissa Coelho PIRES, Cristine Chiodi VETTORI, Adriane de Castro Martines MARTINS

Atualmente acompanhamos uma mudança na atuação da odontologia, que antes era restrita a uma parcela da população e distante dos demais serviços de saúde. Hoje, a odontologia está presente nos principais programas de saúde do governo e apresenta-se integrada a diversos serviços assistenciais de saúde. A mudança na forma de atuar do cirurgião-dentista trouxe a necessidade de mudar o perfil da sua formação acadêmica. Em 2002, essas mudanças iniciaram com o lançamento das Diretrizes Curriculares Nacionais. Neste trabalho relatamos os resultados alcançados pelo estágio curricular do curso de odontologia da Unioeste, desenvolvido no Hospital do Câncer da União Oeste Paranaense de Estudos e Combate ao Câncer - UOPECCAN. Durante os anos de 2006 e 2007, 99 pacientes receberam atendimento odontológico, sendo que 39 eram do gênero feminino e 62 do masculino. A idade dos pacientes variou entre 2 à 84 anos, sendo a neoplasia mais prevalente, o carcinoma epidermóide em região de cabeça e pescoço. $\mathrm{O}$ tratamento odontológico foi realizado em diversos estágios do tratamento oncológico, conforme encaminhamento médico, sendo os procedimentos cirúrgicos, os mais realizados. O desenvolvimento deste estágio permitiu uma integração entre o ensino e o serviço e facilitou o atendimento dos pacientes assistidos pelo Hospital do Câncer.

Palavras chave: Radioterapia; Quimioterapia; Oncologia; Odontologia. 